\title{
Study on the Optimization Effect of Memory on Vocabulary Teaching in Cognitive Psychology
}

\author{
Tan Hongying \\ Jiangxi University of Technology
}

\begin{abstract}
Vocabulary acquisition is an important task in second language acquisition field which has drawn more and more attention, which is the central task and listening, speaking, reading, writing, interpreting cannot get rid of the dependence on vocabulary. Therefore, vocabulary teaching should be given primary importance among priorities. In order to cultivate various abilities of learning English, we have to start from language so as to effectively help students enlarge vocabulary. Besides, to improve the ability of applying vocabulary knowledge is the guarantee to improve the English teaching quality. This paper starts from the perspective of information processing model in cognitive psychology to analyze the effect of memory on vocabulary teaching, aiming to study the effect on foreign vocabulary memorizing based on this theoretical basis. Information processing theory is one of the theories of cognitive psychology, which focuses on the process of receiving, processing and applying information.
\end{abstract}

Keywords-Cognitive psychology; Memory model; Vocabulary Teaching; Information

\section{INTRODUCTION}

Vocabulary is one of the most important in language system as well as primary support for the survival of language system. The size of vocabulary directly affects the language input and output, which also affects students' English level. In English teaching, students always find it difficult to memorize vocabulary and therefore, how to fluently and accurately apply these vocabularies shall be an important problem that English teachers must pay attention to. In cognitive psychology, memory is the reflection of past experience, which can record, keep and replay memory. In order improve learning efficiency, we have to take advantage of memory rule as well as correct memorizing methods. To positively absorb the achievements of memory studies' new results in terms of cognitive psychology shall have optimization effect on English vocabulary learning.

According to the characteristics of memory, important roles of vocabulary in English, we can take vocabulary as an independent course; in order to help students deepen the memory of vocabulary in class, the combination of new words and old words shall be highlighted so as to improve the deep processing of vocabulary and some memory strategies can be introduced to students while songs, pictures can be adopted. The most important is that teachers have to consciously cultivate the habits for students to independently use vocabularies.

\section{THEORY OF MEMORY}

Cognitive psychology believes that memory is to input, encode, store and extract information in the cognitive process which is the reflection of past experience. In general, memory theory includes memory processes and memory structure. Memory process refers to the process to process information into memory while memory structure refers to the components of memory system which are both important to the memory system because in order to permanently save the information, the sensory stimulations have to go through these process.

\section{A. Memory process}

Even though, memory can be divided into code, storage and extraction stages, they are interdependent and influence each other. Code and storage can be beckoned as the extraction prerequisite while extraction and code are results of storage. If information is not encoded in the storage system there won't be memories which can be extracted and if there is no extraction, code and storage shall be meaningless.

\section{B. Memory structure}

Sensory memory is also known as immediate memory, which refers to the recorded prime and instantaneous information storage in the premise of external stimulating the brain, and it is the first step of memory information processing.

Short-term memory is also known as working memory, which refers to the time of processing information and is also the location to grant information with meaning.

Long-term memory is also known as permanent memory which is the main component of human memories which is the storeroom for knowledge with general knowledge such as grammatical rules and arithmetic rules.

\section{PROTOTYPE MEMORY MODEL IN VOCABULARY}

In English teaching, teachers shall teach various vocabularies in one class yet the effect is poor because the volume of short-term memory is small. Besides, the big volume of vocabularies aggravates their burden and interferes the code as well as processing and their 
memories gone before they understand them. Obviously, this situation is not beneficial to their vocabulary learning. Therefore, it is very important to input vocabularies and make it easy to remember. We believe that prototype can solve this problem and its starting point is that basic definitions in memories are related. Some are in the location while some in the edge location. Prototype refers to the practical examples located in the center of certain components which are differentiated and similar while prototype plays as a coordinator. In addition, categorical component is far away from the prototype and it takes long time to be close to it.

Another heuristic point of prototype model is that vocabulary memories can be remembered based on semantic category which can be proved by psychological experiments. Therefore, we can take advantage of the relation between hypernyms and hyponyms to memorize vocabularies. For example, concerning the hypernyms of furniture, they are chair, table, bed etc. So, the division of semantic category can be used to improve memory effect and rapidly enlarge vocabulary.

\section{RELEVANT CONCEPTS OF MEMORY MODEL AND VOCABULARY TEACHING IN COGNITIVE PSYCHOLOGY}

In general, students studying is made up of two systems: regulating system and cognitive system. The former involves the motivation, emotion, and will while the latter involves the internal operation of acquiring knowledge which are entirely different. For example, whether the learning event will become a pressure and ignite anxiety and tension shall be determined by the cognitive appraisal of students; if the evaluation result finds out that this event shall constitute a threat on self-esteem, reputation, status and capacity, it shall be a pressure. It indicates that the operation of cognitive system will affect the status of regulating system. In the contrast, the anxiety and tension will also affect students' attention, memory, problem solving and verbal exposition, that is to say the operation of regulating system also affects the situation of cognitive system.

The information flow chart frequently adopted by information processing theorists to show the process of learning is shown in figure 1:

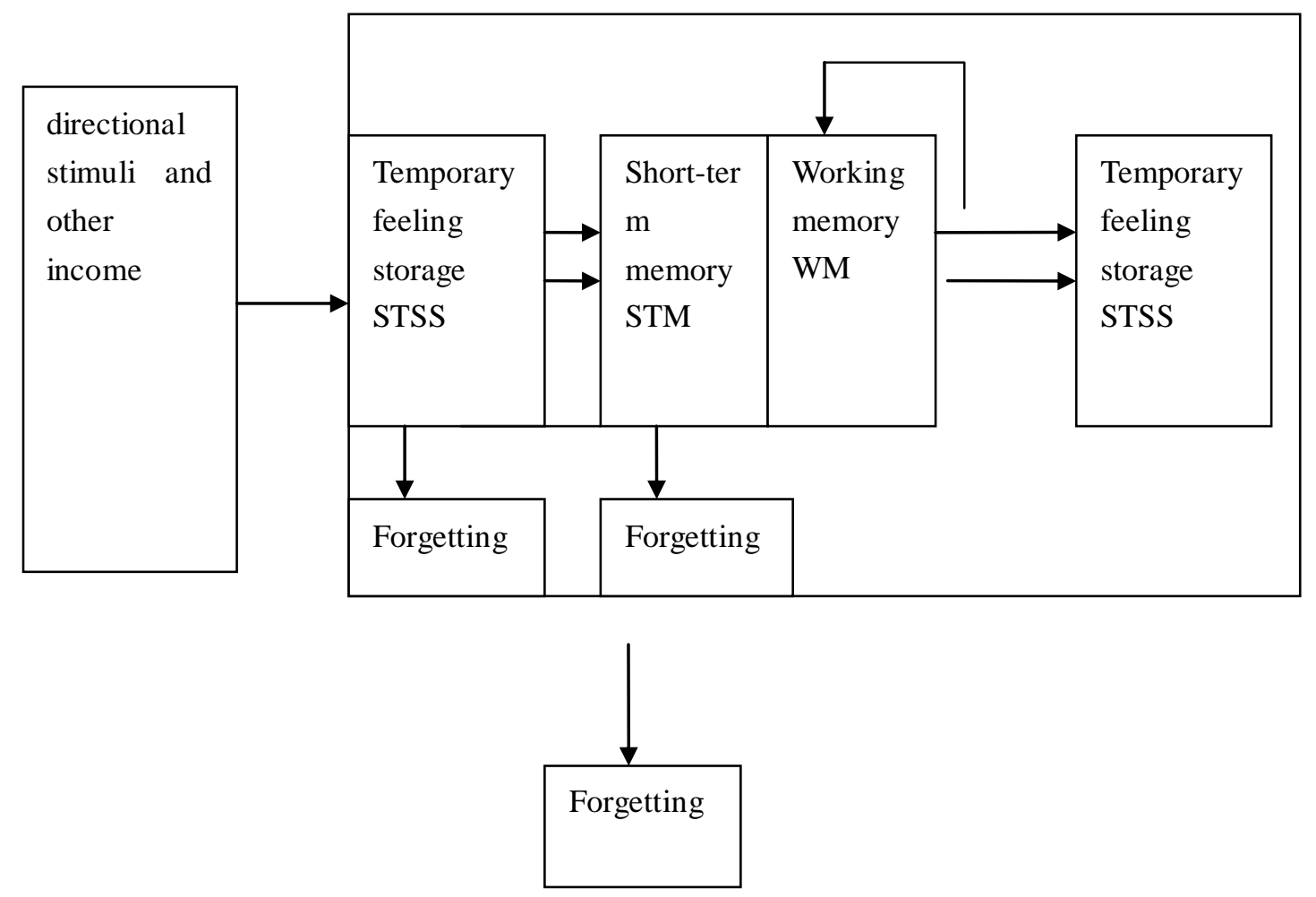

Figure 1. Information flow chart

From this model, we can know that the cognitive learning process includes following stages: first, temporary feeling storage which happens in mutual stimulation between main body and environment. In a moment, various stimulant functions interact in sense organ while only little information enter fields of consciousness and most of them distinct. Second, attention and selective perception, only when the information stored based on temporary feeling is paid attention to, can the information becomes consciousness.
Besides, children shall have selective perception when they concentrate on one thing. Third, memory, which includes short-term memory and long-term memory. The process of cognitive learning is information collecting, processing, storage which can be adopted when necessary.

\section{CONCLUSION}

Based on the researches on cognitive science principle, we can preliminary identify the basic principle 
and general idea of vocabulary learning so find out the breakthrough of vocabulary learning. The general idea of vocabulary teaching is to take communicative approach as the core and cultivate comprehensive communication ability based on systematicness, cognition, emotion and culture.

Overall, the vocabulary memory is an open topic with various approaches and models. From the perspective of the new results in terms of memory research in cognitive psychology we can find out that memory has obvious effect on English vocabulary teaching and scientific teaching approaches shall be important conditions to complete teaching task. To improve cognitive level of vocabulary processing, continually explore new results in scientific field and develop scientific as well as effective teaching methods shall be guarantees to implement excellent English education.

\section{ACKNOWLEDGMENT}

This work was supported by Jiangxi province colleges and universities teaching reform, research topic(No.JXJG-13-24-10)

\section{REFERENCES}

[1] J C, Hinrichs J V, Ghoneim M M. Diazepam and memory: evidence for spared memory function.[J]. Pharmacology
Biochemistry \& Behavior, 1987, 28(3):347-352.

[2] senborn K, Heidenreich S, Giewekemeyer K, et al. Memory function in early hepatic encephalopathy.[J]. Journal of Hepatology, 2003, 39(3):320-325.

[3] ham-Diggory S, Gregg L W. Short-term memory function in young readers[J]. Journal of Experimental Child Psychology, 1975, 19(2):279-298.

[4] lis R A. Memory function during anesthesia.[J]. Anesthesiology, 1999, 90(3):648-650.

[5] lis R A. Memory function during anesthesia.[J]. Anesthesiology, 1999, 90(3):648-650.

[6] n J. Larrabee, Thomas H. Crook III. Performance subtypes of everyday memory function[J]. Developmental Neuropsychology, 1989, 5(4):267-283.

[7] richs R W. Performance on tests of diencephalic-hippocampal verbal memory function in schizophrenia, Korsakoff's syndrome and personality disorder[J]. Schizophrenia Research, 1994, 13(2):127-132.

[8] edy D J, Ogg T W. Alfentanil and memory function[J]. Anaesthesia, 1985, 40(6):537-540.

[9] F Y, Qiu W Y, Liang J R, et al. Determination of memory function and flux on fractals[J]. Physics Letters A, 2001, 288(2):79-87.

[10] E P. Memory function for dressed particles[J]. Journal of Statistical Physics, 1974, 11(6):503-521.

[11] i-Strambi L, Galbiati A, Marelli S. Sleep microstructure and memory function.[J]. Frontiers in Neurology, 2013, 4:159-159.

[12] n B ,. Neuropsychology and advances in memory function[J]. Behavioural Neurology, 1997, 10(4):109-115. 